\title{
Finite element simulation of the effect of loading rate on the stress-strain behaviour of Albany sand
}

\author{
Abu Hena Muntakim¹, Mohammed Saiful Alam Siddiquee ${ }^{2}$ and Kalum Priyanath Udagepola ${ }^{3 *}$ \\ ${ }^{I}$ Faculty of Engineering and Applied Science, Memorial University of Newfoundland, Canada. \\ ${ }^{2}$ Department of Civil Engineering, College of Engineering, King Abdul Aziz University, Jeddah, Saudi Arabia. \\ ${ }^{3}$ Department of Computer Science and Software Engineering, School of Information Technology and Computing, American University of Nigeria, Nigeria.
}

Revised: 05 September 2015; Accepted: 27 November 2015

\begin{abstract}
In this research, the effect of strain rate on Albany sand has been studied by elastic visco-plastic constitutive model within the framework of three component model. Strain rate effect can be modelled by using any one of the (i) Isotach, (ii) TESRA (temporary effects of strain rate and acceleration) or Viscous Evanescent and (iii) P\&N (positive and negative viscosity) models of the three component framework. Usually 'Isotach' is appropriate for clay and soft rock, 'TESRA' for sand and 'P\&N' is appropriate for sand with less angularity like Albany sand. In this research triaxial compression (TC) test results of Albany sand at different strain rates have been modelled successfully into a commercially available package called 'ABAQUS'. The P\&N model was implemented into a generalised elasto-plastic isotropic strain-hardening non-linear model in $\mathrm{C}++$. The model was then embedded in the finite element computer programme ABAQUS, which was used for the actual analysis. In order to define the P\&N model user subroutine of ABAQUS 'UMAT' was written in $\mathrm{C}++$ and used hereafter. ABAQUS is a robust FEM software that allows writing subroutines for describing different material behaviour. Generally UMAT is written in FORTRAN but in this study the main model is written in $\mathrm{C}++$ and then it is called by FORTRAN with appropriate change in ABAQUS environment file. The effect of strain rate on the stress-strain behaviour of Albany sand has been modelled by using the TESRA model with the help of user subroutine UMAT of commercially available FEM software ABAQUS.
\end{abstract}

Keywords: Constitutive law, elasto-plastic model, numerical simulation, $\mathrm{P} \& \mathrm{~N}$ model, three component framework, UMAT.

\section{INTRODUCTION}

In recent times, problems related with long-term creep deformation of sand deposits loaded with a heavy superstructure or secondary consolidation of saturated soft clay including a number of full-scale field cases, have attracted the attention of geotechnical engineers, for correctly understanding and accurately evaluating the viscous properties of geomaterials. Highly non-linear relationships of soil were the main obstacles in soil mechanics. With the development of different experimental and analytical methods, various constitutive models for defining soil behaviour have been published. The effect of strain rate on other materials has also been studied (Khan et al., 2011).

In order to simulate the effects of material viscosity on the stress-strain behaviour of geomaterial (i.e. clay, sand, gravel, and sedimentary soft rock), a set of stressstrain models within the framework of the general non-linear three-component model has been proposed by researchers (Di Benedetto et al., 2002). Three basic viscosity types have been published which are (i) Isotach, (ii) TESRA (temporary effects of strain rate and acceleration) or Viscous Evanescent and (iii) P\&N (positive and negative viscosity). In this research, $\mathrm{P} \& \mathrm{~N}$ viscosity type has been used to simulate the stressstrain behaviour of Albany sand, fine silica sand from Australia. This type of viscosity model is devised to simulate a kind of peculiar material behaviour under variable speed loading.

\section{METHODOLOGY}

The modelling of stress-strain behaviour of geomaterial is very challenging as stress-strain behaviour is highly non-linear in nature. The development of finite element analysis (FEA) has found a way to solve the boundary value problem with highly non-linear material property. 
There are many commercially available FEM software today. Among them ABAQUS is the robust software that allows the user to model their own material model using user subroutine. But the challenge arises when the user wants to write their material model in another language than FORTRAN. In this study, this challenge has been successfully handled as the user subroutine for material model has been written in $\mathrm{C}++$ and used.

\section{Computational setup}

ABAQUS/CAE, or 'complete abaqus environment' (a recursive acronym and backronym with an obvious root in computer-aided engineering) is used for both modelling and analysis of mechanical components and assemblies (pre-processing) and visualising the finite element analysis result. The full computational setup scheme is described here. At first, installation of the finite element software ABAQUS, FORTRAN compiler and $\mathrm{C}++$ compiler is carried out. Then a change is done in windows environment variable to make FORTRAN and $\mathrm{C}++$ compiler available to $\mathrm{CMD}$. After that, a change in ABAQUS environment file is done to make *.lib and *.dll files available for ABAQUS. Finally, the verification procedure of $A B A Q U S$ is carried out to check whether all components are compatible with each other.

The material model code was written in $\mathrm{C}++$ and it was compiled to .dll using $\mathrm{C}++$ compiler. From .dll, using $\mathrm{CMD}$ and $\mathrm{C}++$ compiler the lib file was created. The finite element model was created using ABAQUS/ CAE. Using a FORTRAN interface the material model was called and analysis was performed.

\section{Material model description}

Di Benedetto et al. (2002) successfully simulated the rate dependent stress-strain behaviour of geomaterial observed in a number of laboratory stress-strain tests by the non-linear three-component model (Figure 1) using one-dimensional case.

Figure 2 illustrates the $\mathrm{P} \& \mathrm{~N}$ viscosity type (Tatsuoka et al., 2008b)

In this type of viscosity the viscous stress increment that developed at a given moment during subsequent loading, decays with an increase in instantaneous irreversible strain towards different residual values. The strength during monotonic loading (ML) at a constant strain rate decreases with an increase in strain rate.

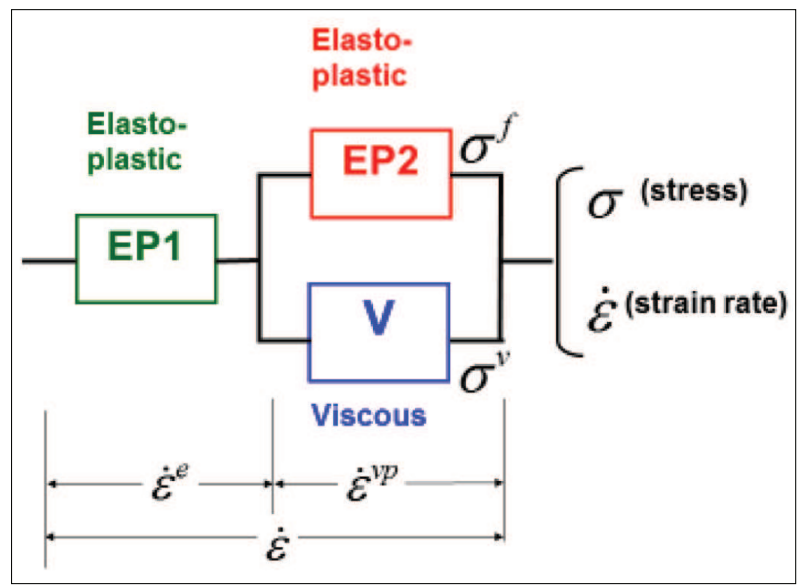

Figure 1: Non-linear three-component model (Di Benedetto \& Tatsuoka, 1997; Di Benedetto et al., 2002)

In the framework (Figure 2) of the three-component model, the measured stress $\sigma$ consists of two parts, which are the inviscid stress component $\sigma^{\mathrm{f}}$, and the viscous stress component $\sigma^{v}$ at the same $\mathcal{E}^{\text {ir }}$. Negative isotech type is a feature of $\sigma^{v}$. Both positive TESRA type component and the negative Isotach type component at the other strain rate are the components of $\sigma^{v}$. This can be observed when a step increase in $\varepsilon$ at point $\mathrm{B}$ during $\mathrm{ML}$ at a constant strain rate. The stress-strain behaviour should be like $\mathrm{A} \rightarrow \mathrm{B} \rightarrow \mathrm{D}$ if there are only negative Isotach type components. But a behaviour like $\mathrm{A} \rightarrow \mathrm{B} \rightarrow \mathrm{C} \rightarrow \mathrm{D}$, instead of $\mathrm{A} \rightarrow \mathrm{B} \rightarrow \mathrm{D}$ is observed in poorly graded relatively round and stiff-particle granular material. A step increase in $\dot{\varepsilon}(\mathrm{B} \rightarrow \mathrm{C})$ results in the same amount of immediate positive stress increase when the viscosity type is

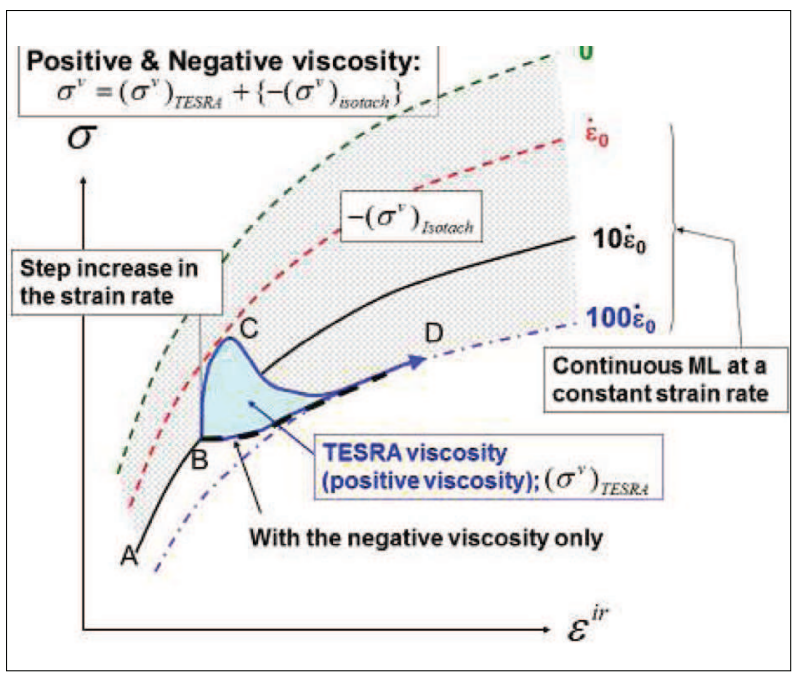

Figure 2: Illustration of $\mathrm{P} \& \mathrm{~N}$ viscosity 
Isotach or combined or TESRA. After that, subsequent ML at a constant $\dot{\varepsilon}$ results in the decrease of $\sigma^{v}$ from a temporarily increased value $(\mathrm{C} \rightarrow \mathrm{D})$ like the TESRA type. This feature was also found in the stress-strain behaviour of Albany sand. For this reason the P\&N model is the appropriate viscosity type for simulating viscosity of Albany sand.

\section{Experimental setup}

From the laboratory experiments (Tatsuoka et al., 2008a) it was found that four poorly graded granular materials, named, a) corundum A (aluminium oxide, $\left.\mathrm{Al}_{2} \mathrm{O}_{3}\right)$, an artificial material $\left(\mathrm{e}_{\max }=1.066\right.$ and $\mathrm{e}_{\text {min }}$ $=0.865)$; b) Albany sand, a fine silica sand from Australia $\left(\mathrm{e}_{\max }=0.804\right.$ and $\left.\left.\mathrm{e}_{\min }=0.505\right) ; \mathrm{c}\right)$ hime gravel, a natural fine gravel from a river bed in the Yamanashi Prefecture, Japan $\left(\mathrm{e}_{\max }=0.759\right.$ and $\mathrm{e}_{\min }=$ $0.515)$; and d) Monterey No. 0 sand, a natural fine beach sand from the USA $\left(\mathrm{e}_{\max }=0.860\right.$ and $\mathrm{e}_{\min }=$ 0.550 ), exhibited the $P \& N$ viscosity in the drained TC tests. In this paper, the experimental results of Albany sand are the main focus. The particle shape and size is shown in Figure 3. The specific gravity was 2.64. Its maximum void ratio and minimum void ratio were $\mathrm{e}_{\max }=0.804$ and $\mathrm{e}_{\min }=0.505$, respectively.

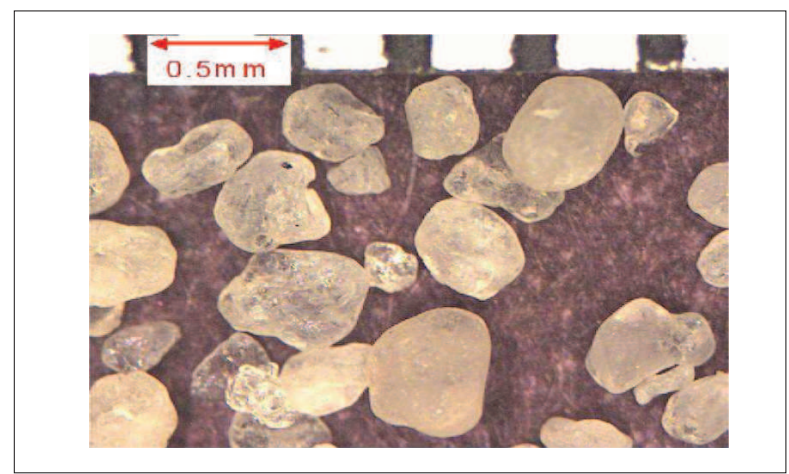

Figure 3: Particle shape and size of Albany sand

Loose and dense cylindrical specimens of diameter $70 \mathrm{~mm}$ and height $150-155 \mathrm{~mm}$ were prepared from Albany sand. The experiments were performed on air-dried specimens to keep the loading rate effects out of the effects of delayed dissipation of excess pore water pressure. The schematic diagram of the experiment is shown in Figure 4.

A $0.3 \mathrm{~mm}$ thick latex rubber disc smeared with a $0.05 \mathrm{~mm}$ thick silicon grease layer (Tatsuoka et al., 1984) was used at the top and bottom ends of each specimen. An external deformation transducer and a pair of local

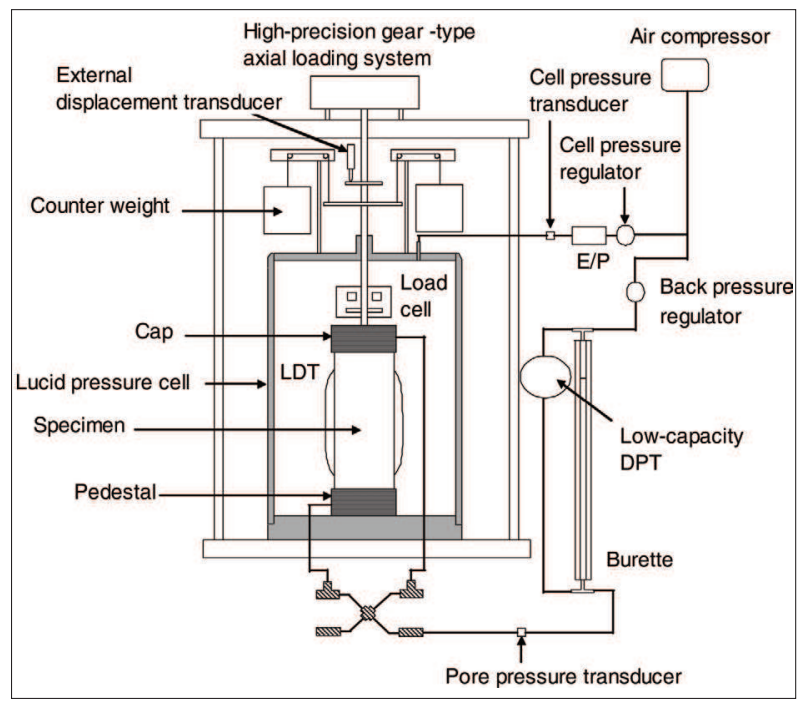

Figure 4: Automated triaxial apparatus used in the present study

deformation transducers (LDTs) (Goto et al., 1991), which had a gauge length of about $12 \mathrm{~cm}$, was used to measure axial deformation. The homogeneity in the zone of before and after peak was not possible to evaluate. The reason for this has been discussed by Tatsuoka et al. (1990) and it was shown that local share bands start developing before the pick stress state in drained plane strain compression (PSC) tests on dense sand. Locally measured axial strains were used to calculate the elastic deformation properties. Based on the modified Rowe's stress-dilatency relation, the volume change of air dried specimen was estimated. These experiments were done using an automated triaxle apparatus (Santucci de Magistris et al., 1999).

The specimens were loaded automatically. To control the cell pressure, a high precision gear-type axial loading system driven by a servo-motor together with an electric pneumatic pressure transducer was used. By increasing the effective stress from $20 \mathrm{kPa}$ towards $400 \mathrm{kPa}$ at an axials strain rate of $0.0625 \% / \mathrm{min}$, the isotropic compression was performed. During the isotropic compression process to evaluate the vertical quasi-elastic Young's modulus, eight cycles of axial strain (double amplitude) of $0.001-0.003 \%$ were applied at $\mathrm{p}=50,100,200$ and $300 \mathrm{kPa}$. Figure 5 shows the results from CD TC tests at different vertical strain rates on air dried Albany sand.

\section{Pseudo-algorithm}

Siddiquee et al. (2006) have developed the pseudoalgorithm, which was the revised form of the original solution technique of the DR method. Viscous effects were not included. 


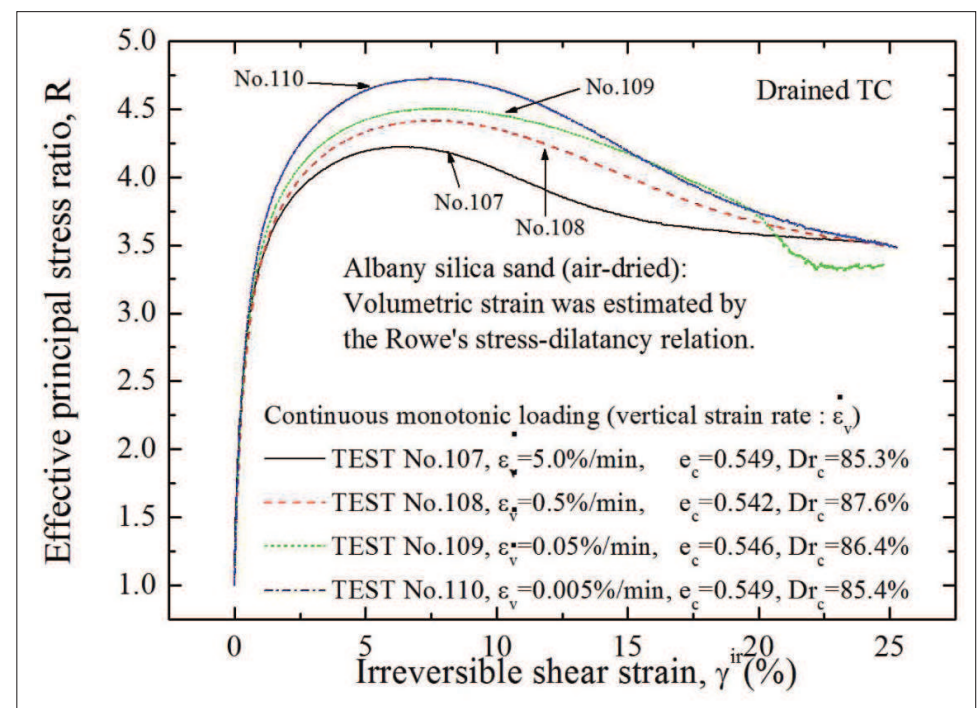

Figure 5: Results from $\mathrm{CD}$ TC tests at different vertical strain rates on air dried dense Albany silica sand

In the return mapping algorithm (Ortiz \& Simo, 1986), incremental elasto-plastic equations are solved at the first level of integration. Satisfying the consistency condition (abiding by the flow rule), the stress is returned to the growing yield surface. When calculating the viscous stress based on the P\&N model, the stress is returned to the inviscid yield surface with an incremental integration during the second level of integration when it is necessary at each step of return mapping iteration. This scheme is presented in Figure 6.

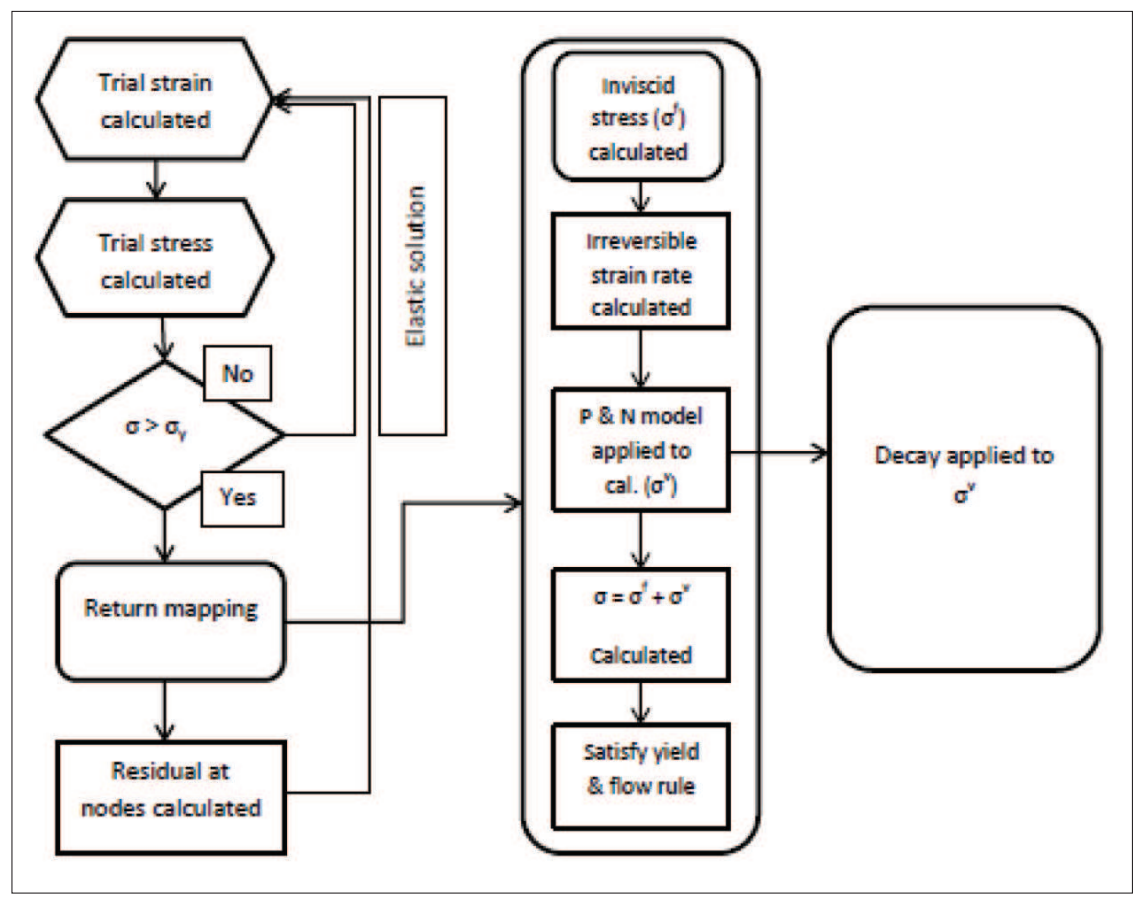

Figure 6: Implementation of the P\&N model into a FEM code 


\section{Overall model calculation functions}

In the user subroutine UMAT, the stress and hardening softening parameters are calculated from the strain and elastic modulus provided by ABAQUS. With the updated stress and hardening softening parameters ABAQUS carry out the non-linear boundary solution and provide strain and elastic modulus to UMAT. In this process the whole analysis is completed. The main function of user subroutine UMAT is UMAT_CPP. In UMAT_CPP the strain calculated by the ABAQ Q input and it calculates the stress in that given moment. At the end of this function, the stress is updated to ABAQUS. In this function the elastic modulus is calculated from Young's modulus and Poisson ratio. Failure surface is calculated in the function ReternMapping_. PlsticModel_function calculates the reference curve. The function yldchk calculates the yield function. The calculation of invariants is done in the function invar. The potential function and yield function is calculated in the function yieldf.

\section{Details of the model}

\section{Parameters used}

Tatsuoka et al. (2008b) described various aspects of the simulation and represented simulation parameters for the stress-strain behaviour exhibiting the $\mathrm{P} \& \mathrm{~N}$ viscosity.

\section{Elasto-plastic framework}

The present study is done using the generalised elastoplastic isotropic strain-hardening and softening model, which takes into account strain localisation associated with shear banding by introducing a characteristic width of shear band in the additive elasto-plastic decomposition of strain (Tatsuoka et al., 1993). The yield function is used as follows:

$\Phi=-\eta I_{1}+\frac{1}{g(\theta)} \sqrt{J_{2}}-K$

Equation (1) is used as the growth function of the yield surface of the generalised Mohr-Coulmb type. $I_{1}$ is the first stress invariant (i.e. hydrostatic stress component, positive in compression) and $J_{2}$ is the second deviatoric stress invariant (i.e. the deviatoric stress). Siddiquee et al. (1999; 2001) and Siddiquee and Tatsuoka (2001) have explained in detail about the growth function.

The plastic potential function, $\psi$, is defined as;

$\psi=-\alpha I_{1}+\sqrt{J_{2}}-K$

This plastic potential function of the Drucker-Prager type is similar to the yield function except that $g(\Theta)$ in equation (1). Here in the analysis, stress dependent elastic parameters are used.

Table 1: Viscosity parameters used to analyse the CD triaxial tests

\begin{tabular}{|c|c|c|c|c|c|c|c|c|c|c|c|c|}
\hline \multirow[t]{2}{*}{ Material } & \multirow[t]{2}{*}{$\begin{array}{c}\text { Strain } \\
\text { parameter }\end{array}$} & \multirow[t]{2}{*}{$\begin{array}{l}\beta \text { : test } \\
\text { results }\end{array}$} & \multicolumn{3}{|c|}{$\begin{array}{l}\text { Parameters in the } \\
\text { viscosity function }\end{array}$} & \multicolumn{2}{|c|}{$\begin{array}{c}\text { Back-calculated } \\
\text { by fitting }\end{array}$} & \multirow[t]{2}{*}{$\begin{array}{c}\text { Decay } \\
\text { parameter }\end{array}$} & \multicolumn{4}{|c|}{$\begin{array}{l}\text { Viscosity type } \\
\text { parameter, } \Theta\end{array}$} \\
\hline & & & $\alpha$ & $\mathrm{m}$ & $\varepsilon_{\mathrm{r}}^{\text {.ir }}$ & $\mathrm{b}$ & $\beta$ : from $b$ & & $\Theta_{\mathrm{ini}}$ & $\Theta_{\text {end }}$ & $\mathrm{c}$ & $\varepsilon_{\theta}$ ir: $\%$ \\
\hline Albany sand & $\begin{array}{l}\text { Irreversible } \\
\text { shear strain }\end{array}$ & 0.0195 & 0.24 & 0.04 & $\begin{array}{l}1.0 \mathrm{E}-5 \\
(\% / \mathrm{s})\end{array}$ & 0.00827 & 0.0190 & $1.0 \mathrm{E}-03$ & -0.3 & -1.0 & 1.0 & 12 \\
\hline
\end{tabular}

\section{RESULTS AND DISCUSSION}

In this study, experimental results of four TC tests of different strain rates have been simulated successfully. All the stress-strain relationships depended on the rate of straining. The most innovative idea of this research was the modelling of the effect of strain rate on the shear strength of Albany sand. Usually most geomaterials increase in strength with the increase in rate of straining, but here in this case, the strength of Albany sand is reduced with the increase in rate of straining. The opposite effect of the rate of straining on Albany sand might have effects on the post-peak behaviour of the sand. It has been found that the FEM simulation matched the experimental data quite well up to the peak, and then it started to deviate. This tendency may be attributed to the non-unique nature of solution at the post peak range of the stress-strain behaviour. Further studies on the behaviour on the post-peak of Albany sand is underway.

In Figure 7 the simulated curve has been compared with the experimental data of TC test at a vertical strain rate $5.0 \% / \mathrm{min}$. In this simulation the peak effective principal stress was 4.22 at irreversible shear strain $6.6 \%$. The simulated curve is largely deviated from the experimental curve after an irreversible shear strain of $13.4 \%$. 


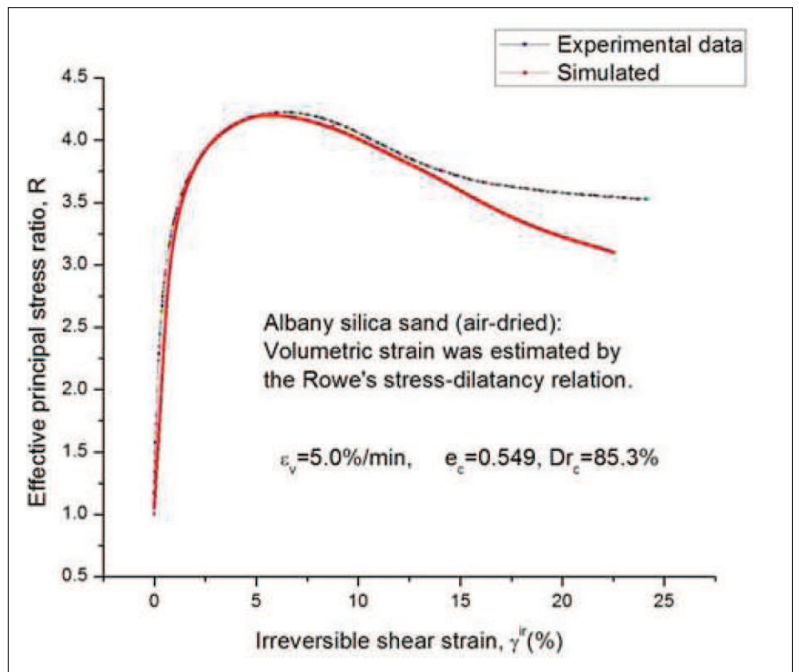

Figure 7: Experimental and simulated curve of effective principal stress, $\mathrm{R} v s$ irreversible shear strain at a vertical strain rate $5.0 \% / \mathrm{min}$

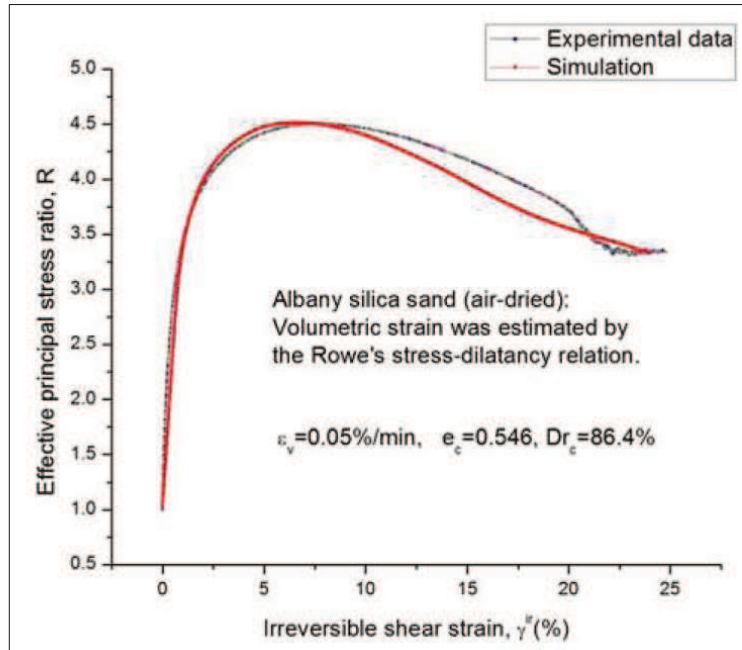

Figure 9: Experimental and simulated curve of effective principal stress, $\mathrm{R} v s$ irreversible shear strain at a vertical strain rate $0.05 \% / \mathrm{min}$

In Figure 8 the simulated curve has been compared with the experimental data of TC test at a vertical strain rate $0.5 \% / \mathrm{min}$. In this simulation the peak effective principal stress was 4.4 at an irreversible shear strain of $8.2 \%$. The simulated curve is largely deviated from the experimental curve after an irreversible shear strain of $5.51 \%$.

In Figure 9 the simulated curve has been compared with the experimental data of TC test at a vertical strain rate $0.05 \% / \mathrm{min}$. In this simulation the peak effective principal

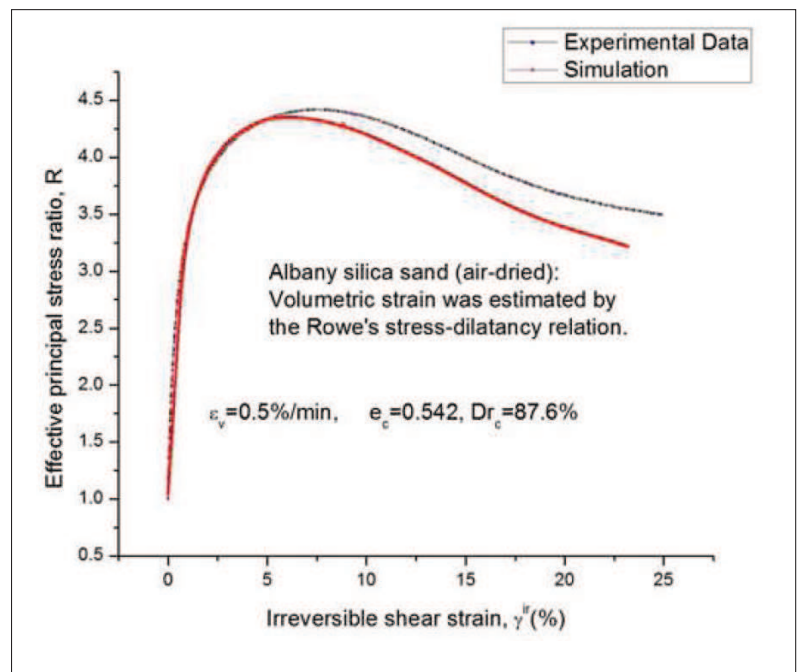

Figure 8: Experimental and simulated curve of effective principal stress, $\mathrm{R} v s$ irreversible shear strain at a vertical strain rate $0.5 \% / \mathrm{min}$

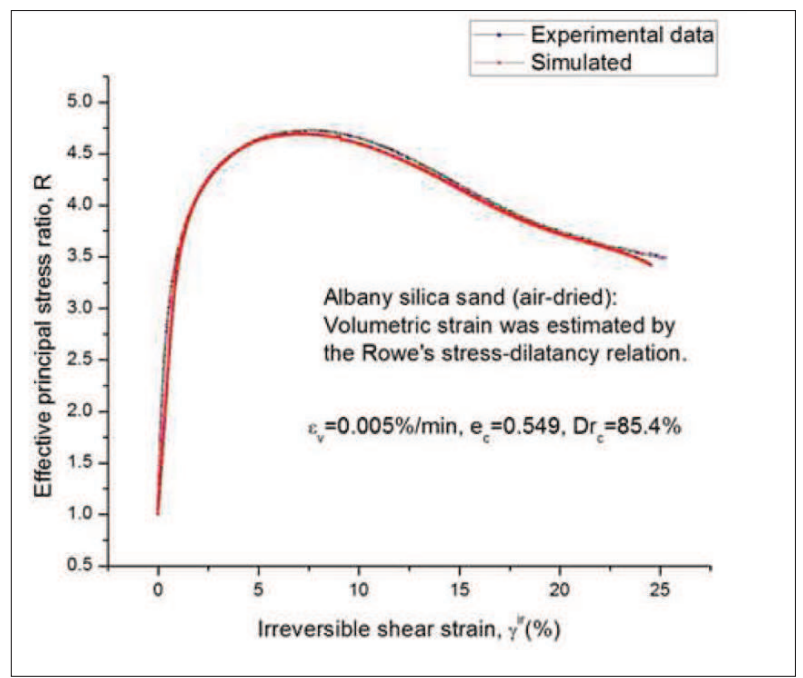

Figure 10: Experimental and simulated curve of effective principal stress, $\mathrm{R} v s$ irreversible shear strain at a vertical strain rate $0.005 \% / \mathrm{min}$

stress was 4.5 at an irreversible shear strain of $7.5 \%$. The simulated curve is largely deviated from the experimental curve after an irreversible shear strain of $9.4 \%$.

In Figure 10 the simulated curve has been compared with the experimental data of TC test at a vertical strain rate $0.005 \% / \mathrm{min}$. In this simulation the peak effective principal stress was 4.7 at an irreversible shear strain of $7.15 \%$. As this curve is accounted as base, the simulated and experimental curve is nearly the same. 


\section{CONCLUSION}

In this research a visco-elasto-plastic model is used within the framework of three-component material model. The model is implemented as UMAT of commercially available software called ABAQUS. The effect of strain rate on Albany sand has been studied by the combination of elastic visco-plastic constitutive law and three component framework. The following conclusions can be drawn from this study.

TC test results of Albany sand at different strain rates have been modelled successfully into a commercially available package called ABAQUS using an unconventional approach. The P\&N model was implemented into a generalised elasto-plastic isotropic strain-hardening nonlinear model in $\mathrm{C}++$. The model is then embedded in the finite element computer programme ABAQUS.

The experimental data was successfully simulated up to the peak strain but the problem was that simulation deviated significantly in large deformation range. The simulated curve was deviated more or less from $7.5 \%$ irreversible shear strain. The deviation was higher for vertical strain rate at $0.3 \% / \mathrm{min}$.

In this study user subroutine was written in $\mathrm{C}++$ rather than FORTRAN. With the help of $\mathrm{C}++$ compiler .dll and .lib files were created and they were placed in an appropriated destination and the environmental file was updated. This made possible to call the user subroutine from FORTRAN and simulation of stress-strain behaviour of Albany sand.

\section{Acknowledgement}

The contribution of the Geotechnical Engineering Laboratory of the University of Tokyo, Japan is highly appreciated.

\section{REFERENCES}

1. Di Benedetto H. \& Tatsuoka F. (1997). Small strain behaviour of geomaterials: modelling of strain effects. Soils and Foundations 37(2): 127 - 138.

DOI: http://dx.doi.org/10.3208/sandf.37.2_127

2. Di Benedetto H., Tatsuoka F. \& Ishihara M. (2002). Timedependant shear deformation characteristics of sand and their constitutive modelling. Soils and Foundations 42(2): 1 - 22. DOI: http://dx.doi.org/10.3208/sandf.42.2_1

3. Goto S., Tatsuoka F., Shibuya S., Kim Y.S. \& Sato T. (1991). A simple gauge for local small strain measurements in the laboratory. Soils and Foundations 31(1): $169-180$. DOI: http://dx.doi.org/10.3208/sandf1972.31.169
4. Khan A.S., Pandey A., Gnäupel-Herold T. \& Mishra R.K. (2011). Mechanical response and texture evolution of AZ31 alloy at large strains for different strain rates and temperatures. International Journal of Plasticity 27(5): $688-706$.

DOI: http://dx.doi.org/10.1016/j.ijplas.2010.08.009

5. Ortiz M. \& Simo J.C. (1986). An analysis of a new class of integration algorithms for elasto-plastic constitutive relations. International Journal for Numerical Methods in Engineering 23: 353 - 366 .

DOI: http://dx.doi.org/10.1002/nme.1620230303

6. Santucci de Magistris F., Koseki J., Amaya M., Hamaya S., Sato T. \& Tatsuoka F. (1999). A triaxial testing system to evaluate stress-strain behaviour of soils for wide range of strain and strain rate. Geotechnical Testing Journal 22(1): $44-60$. DOI: http://dx.doi.org/10.1520/GTJ11315J

7. Siddiquee M.S.A., Tatsuoka F., Tanaka T., Tani K. \& Morimoto T. (1999). FEM simulation of scale effect in bearing capacity of strip footing on sand. Soils and Foundations 34(4): 91 - 109.

8. Siddiquee M.S.A., Tatsuoka F., Tanaka T., Tani K., Yoshida K. \& Morimoto T. (2001). Model tests and FEM simulation of some factors affecting the bearing capacity of footing on sand. Soils and Foundations 41(2): 53 - 76.

DOI: http://dx.doi.org/10.3208/sandf.41.2_53

9. Siddiquee M.S.A. \& Tatsuoka F. (2001). Modelling time dependant stress-strain behaviour of stiff geomaterials and its applications. Proceedings of the $10^{\text {th }}$ International Conference on Computer Methods and Advances in Geomechanics (IACMAG), 7 - 12 January, Tucson, Arizona, USA.

10. Siddiquee M.S.A., Tatsuoka F. \& Tanaka T. (2006). Fem simulation of the viscous effects on the stress-strain behaviour of sand in plane strain compression. Soils and Foundations 46(1): 99 - 108. DOI: http://dx.doi.org/10.3208/sandf.46.99

11. Tatsuoka F., Di Benedetto H., Kongkitkul W., Kongsukprasert L. \& Nishi T. (2008a). Modelling of ageing effects on the elastoviscoplastic behaviour of geomaterial. Soils and Foundations 48(2): 155 - 174.

DOI: http://dx.doi.org/10.3208/sandf.48.155

12. Tatsuoka F., Di Benedetto H., Enomoto H., Kawabe T. \& Kongkitkul W. (2008b). Various viscosity types of geomaterials in shear and their mathematical expression. Soils and Foundations 48(1): $41-60$.

DOI: http://dx.doi.org/10.3208/sandf.48.41

13. Tatsuoka F., Molenkamp F., Torii T. \& Hino T. (1984). Behaviour of lubrication layers of platens in element tests. Soils and Foundations 24(1): 113 - 128.

DOI: http://dx.doi.org/10.3208/sandf1972.24.113

14. Tatsuoka F., Nakamura S., Huang C.C. \& Tani K. (1990). Strength anisotropy and shear band direction in plane strain tests on sand. Soils and Foundations 30(1): 35 - 54.

DOI: http://dx.doi.org/10.3208/sandf1972.30.35

15. Tatsuoka F., Siddiquee M.S.A., Park C.S., Sakamooto M. \& Abe F. (1993). Modelling stress-strain relations of sand. Soils and Foundations 33(2): $60-81$. 